\title{
EDITORIAL
}

\section{What is 'organic'? organic chemistry, organic fertilizer and organic agriculture}

The historical connotation of the word 'organic' was a connection with processes in nature involving life. Thus, 'organic chemistry' was the chemistry of natural substances obtained from animals and plants. These substances were considered to possess a vital force which made them different from substances obtained from non-living matter such as minerals. The idea of a vital force gradually receded with the realization that at least some of the substances produced by living organisms could also be produced in the laboratory, starting from inorganic materials. Wöhler's observation in 1828 , that urea could be obtained by heating ammonium cyanate, was a landmark experiment in this narrative. As the vast majority of the so-called organic compounds contained carbon, and the compounds of carbon exceed in number those of all the other elements, the term 'organic chemistry' has evolved to its current meaning today, to be the chemistry of carbon containing compounds.

The term 'organic agriculture' uses the word 'organic' in its original sense of connection with living processes in a holistic manner. Thus, one of the key principles of organic agriculture is that the farming of food crops should be carried out in a way which sustains and enhances the health of soil, plants, animals and humans; and should be based on living ecological systems and cycles.

However, the use of the word 'organic' in the term 'organic fertilizer' is ambiguous, unlike in the terms 'organic chemistry' and 'organic agriculture'. For example, urea, which is widely used as a fertilizer is produced industrially by the reaction of ammonia (from the Haber process) with carbon dioxide, is also produced by mammals as a by-product of protein metabolism.

There has been much controversy recently in Sri Lanka, regarding the importation and utilization of fertilizer, after the government of Sri Lanka stated its policy of converting to organic agriculture. It was taken for granted (incorrectly) that organic agriculture requires only 'organic fertilizer'. The controversy was partly due to the usage in public debate, of the Sinhala language word for 'organic' (which can be transcribed as "carbonica") which connotes a relationship to the element carbon, rather than to 'living' or 'natural'. The usage of the vague term 'chemical fertilizer' in the sense of being the opposite of 'organic fertilizer' confused the debate further. For example, was urea an organic fertilizer or a chemical fertilizer? Was a mineral containing potassium an organic fertilizer, chemical fertilizer or a different kind altogether called an inorganic fertilizer?

Most of the protagonists in this controversy, like Humpy-Dumpty in Lewis Carroll's story, "Through the Looking Glass" have used the word 'organic' to mean just what they "choose it to mean". As in any scientific debate, definition and agreement on the meaning of the terms used is necessary for clarity of thought required to arrive at sound conclusions.

Ajit Abeysekera 